J Marriage Fam. 2014 October 1; 76(5): 967-982. doi:10.1111/jomf.12137.

\title{
A Social Network Comparison of Low-Income Black and White Newlywed Couples
}

\author{
Grace L. Jackson, \\ University of California, Los Angeles \\ David Kennedy ${ }^{*}$, \\ RAND Corporation \\ Thomas N. Bradbury** and \\ University of California, Los Angeles \\ Benjamin R. Karney $^{\star \star \star}$ \\ University of California, Los Angeles
}

\begin{abstract}
Relative to White families, Black families have been described as relying on extended social networks to compensate for other social and economic disadvantages. The presence or absence of supportive social networks should be especially relevant to young couples entering marriage, but to date there has been little effort to describe the social networks of comparable Black and White newlyweds. The current study addressed this gap by drawing on interviews with 57 first-married newlyweds from low-income communities to compare the composition and structure of Black and White couples' duocentric social networks. The results indicated that low-income Black couples entered marriage at a social disadvantage relative to White couples, with more family relationships but fewer positive relationships and fewer sources of emotional support (for wives), fewer connections to married individuals, and fewer shared relationships between spouses. Black couples' relative social disadvantages persisted even when various economic and demographic variables were controlled.
\end{abstract}

\section{Keywords}

Blacks; couples; family systems; low-income families; marriage; peer relationships

Black families have long been described as drawing support from their extended social networks (McAdoo, 1998; Stack, 1974; Staples \& Johnson, 1993). Indeed, analyses of data from the National Survey of Black Americans indicate that 2 out of 3 Black adults treat someone to whom they are not biologically related as a relative (Chatters, Taylor, \& Jayakody, 1994). Furthermore, ethnographic research on Black families suggests that strong expectations about mutual support continue to play a large role in these extended network

\footnotetext{
Department of Psychology, University of California, 1285 Franz Hall, Los Angeles, CA 90095 (email[KAS1]).

*RAND Corporation, 1776 Main St., M5S, Santa Monica, CA 90407-2138.

*** Department of Psychology, University of California, 4560 Franz Hall, P.O. Box 951563, Los Angeles, CA 90095-1563.

*** Department of Psychology, University of California, 4560 Franz Hall, P.O. Box 951563, Los Angeles, CA 90095-1563.
} 
ties (e.g., Hill, 1999; Roy, 2005). The cultivation of extended networks may be a source of social capital for Black families to compensate for experiences of segregation and economic hardship (Broman, 1996; Scott \& Black, 1999).

To the extent that extended social networks can serve as a source of social capital for Black families, they may be especially relevant for Black married couples. On several dimensions, Black couples enter marriage at a disadvantage relative to comparable Whites. Not only do Black couples have less access to education and higher rates of unemployment than Whites, they are also overrepresented in lower income communities in the United States (Macartney, Bishaw, \& Fontenot, 2013), significantly less likely to get married and thus rare within Black communities (Bramlett \& Mosher, 2002), and significantly more likely to have children prior to entering marriage (Elwood \& Jencks, 2004). If Black couples possess the extended social networks that have been described as characteristic of Black families more generally, those networks might serve as a resource to compensate for these other social and economic disadvantages.

Yet, although research has described the social networks of Black families, research directly comparing the networks of Black and White couples has been rare. Moreover, the limited existing literature has relied almost exclusively on global perceptions of network quality, preventing detailed statements of how the composition and structure of Black couples' social networks may differ from those of comparable White couples. Recognition of this gap has instigated a call for further research describing the social networks of disadvantaged populations (Sampson, Morenoff, \& Gannon-Rowley, 2002) and of Black couples in particular (Brown, Orbuch, \& Maharaj, 2010; Bryant et al., 2010). In the current study we aimed to fill this gap in the literature by using newly developed techniques of social network analysis (i.e., studying couples' combined duocentric social networks; Kennedy, Jackson, Bradbury, Green, \& Karney, 2014) to compare the networks of recently married Black and White couples sampled from low-income communities.

\section{Differences In the Composition of Black and White Couples' Social Networks}

The composition of a social network refers to the aggregated characteristics of the individuals who compose the network. Qualitative and quantitative research suggests at least two ways that the composition of Black and White couples' social networks may differ.

First, Black and White couples may differ in the amount of emotional and financial support they can access from their networks. Several studies have shown that Blacks generally describe smaller networks of close relationships than comparable Whites but, within their networks, Blacks generally describe a higher proportion of family members (Ajrouch, Antonucci, \& Janevic, 2001). In light of the fact that people are more likely to draw social support from family members than from friends or coworkers (Wellman \& Wortley, 1990), these trends suggest that low-income Black couples may possess stronger networks of support (both emotional and financial) than comparable White couples, consistent with the idea that social networks may partly compensate for economic disadvantages in Black communities (Broman, 1996; McAdoo, 1998). Research on couples in established 
marriages, however, has found that Black couples actually report receiving less family support than White couples (Rhodes, Ebert, \& Meyers, 1994; Timmer, Veroff, \& Hatchett, 1996). One reason may be that Black couples are often expected to provide support to their network members rather than receive it. Indeed, even Black couples in satisfying, established relationships describe the demands of their extended networks as a leading source of stress (Marks et al., 2008). For Black newlyweds, therefore, network relationships may not provide the financial and emotional assistance that helps sustain White couples (Neighbors, 1997) and instead may act as yet another disadvantage Black couples face.

Second, to the extent that rates of marriage are lower and rates of divorce are higher among Blacks than among Whites (Bramlett \& Mosher, 2002), Black couples' networks may contain fewer models of successful marriage than White couples' networks. The transmission of expectations through a network has been invoked to account for marital outcomes in disadvantaged communities, where the presence of married couples in a couple's network may convey the idea that "family stability is the norm, not the exception" (Wilson, 1987, p. 56). Longitudinal data support this perspective, showing that the greater the proportion of married people in spouses' networks and the fewer network members who are divorced, the greater the longevity of a couple's marriage, even after controlling for potential confounds such as income and education (Booth, Edwards, \& Johnson, 1991; McDermott, Fowler, \& Christakis, 2009). If the networks of recently married Black couples contain fewer married individuals and more divorced individuals, then they may have less exposure to examples of successful long-term relationships.

\section{Differences In the Structure of Black and White Couples' Networks}

The structure of a social network refers to the arrangement of relationships among network members, independent of the characteristics of those individuals. Structural features of social networks have been studied less often than compositional features, but there are reasons to predict that the structure of Black and White couples' social networks may differ as well.

First, Black and White couples may differ in the density of their networks, that is, the proportion of network members with relationships to one another. Because Black families are more likely to have been disrupted by divorce or to have experienced multiple partner fertility (Bramlett \& Mosher, 2002), gaps left by a lack of married familial ties may be filled with friends and coworkers who do not know one another. As a consequence, the networks of Black couples may have fewer interconnections than the networks of White couples (Harknett \& Knab, 2007). To the extent that networks with more connections are more efficient at transferring information and resources throughout the network (Centola, 2010), lower density networks with fewer connections would represent an additional impediment to garnering needed support for Black couples.

Second, Black and White partners may differ in the degree to which their spouses are connected to other people within their networks, a structural feature referred to as centrality (Wasserman \& Faust, 1994). Spouse centrality may contribute to marital outcomes in two ways. First, a spouse with high centrality (i.e., connected to many individuals in the 
partner's network) can coordinate and draw on other network members who otherwise would have no contact with each other, facilitating the transfer of information and resources when they are needed. Second, a well-connected spouse may reflect partners who have integrated their spouses within their own networks. Ties between one's spouse and other networks members may represent a barrier to ending the marriage, because leaving the spouse may threaten other valued relationships as well. Prior research in this area has not assessed spouse centrality directly, but research from the Early Years of Marriage Project has shown that Black spouses do report feeling less close to each other's families (Orbuch, Bauermeister, \& Brown, 2008), suggesting that Black spouses may be less well integrated into each other's networks than White spouses.

\section{Differences in Black and White Couples' Duocentric Networks}

To date, comparisons of the social networks of Black and White couples have focused exclusively on networks surrounding individuals, known as egocentric networks. Collecting data from couples, however, provides an opportunity to describe the combined networks of two people, known as duocentric networks (Coromina, Guia, Coenders, \& Ferligoj, 2008; Kennedy et al., 2014). With respect to understanding marriages, an advantage of assessing duocentric networks is the ability to estimate overlap, that is, the number of individuals appearing in both spouses' networks. Greater overlap within the duocentric network may promote marriages through direct pressure to remain together exerted by individuals close to both partners (Sprecher, 2011) or through shared social investments that constrain partners from leaving the marriage. Indeed, couples who perceive more shared ties are more satisfied with their relationships cross-sectionally (e.g., Julien, Chartrand, \& Begin, 1999; Stein, Bush, Ross, \& Ward, 1992) and describe more satisfying and lasting relationships longitudinally (e.g., Burger \& Milardo, 1995; Kearns \& Leonard, 2004). Given that Black spouses feel less close to each other's families than White spouses, Black couples may include fewer of each other's family members among their shared ties and thus have less overlap overall as compared to White couples. Prior comparisons of the networks of Black and White couples in established relationships have not assessed actual duocentric overlap directly, instead relying on global perceptions of overlap that can be biased by perceptions of relationship satisfaction and do not correlate perfectly between partners.

A second advantage of duocentric network assessments is the opportunity they provide to describe the characteristics of spouses' shared network members. Black couples' overlap may not only be smaller than that of White couples but also, to the extent that Black spouses generally feel less close to their spouses' family than White couples do (Orbuch et al., 2008), less likely to include family members as well. In addition, when couples do share ties to the same individuals, they may not agree on the quality of those relationships. A higher proportion of discordant relationships-that is, when one partner reports a positive relationship with an individual and the other reports a neutral or negative relationship with that individual — may be a risk factor for couples that research on their social networks has yet to examine. 


\section{Limitations of Prior Research}

Whereas ethnographic research suggests that strong social network ties may be a characteristic strength of Black families (Hill, 1999; McAdoo, 1998), prior studies describing social networks among Blacks and Whites suggest that Black couples may enter their marriages at a social disadvantage relative to White couples (Lawson \& Thompson, 1994). The existing literature cannot resolve these two competing perspectives because of several limitations of prior research. First, prior investigations of social networks have relied exclusively on spouses' own global perceptions of the composition of their networks, preventing descriptions of structural features, such as density and overlap, that may be independently informative (Allan, 2006). Second, the few studies that have asked partners to list specific network members generally restrict their lists to between five and 11 individuals. Lists of this size produce unreliable estimates of structure (Golinelli et al., 2010) and are unlikely to get beyond family members and closest friends, thus ignoring the peripheral and weaker ties (i.e., casual relationships with neighbors or coworkers) that some suggest are especially important for connecting individuals with new opportunities and information (Marsden, 2005).

Third, comparisons of Black and White social networks have generally collected Black and White samples from different communities and have neglected to control for economic and demographic differences between Black and White couples. Compared to White couples, Black couples typically marry later (Landale \& Oropesa, 2007), are more likely to have children prior to entering marriage (Elwood \& Jencks, 2004), and report lower incomes (Fronczek, 2005). Each of these differences has implications for social networks. For example, as individuals age they generally focus more on a smaller group of closer ties within their networks, devoting less attention to peripheral contacts (Ajrouch et al., 2001; Carstensen, 1992). As couples transition into parenthood, they tend to increase contact with family, request more support from them, and have less contact with friends (Bost, Cox, \& Payne, 2002). Finally, individuals of lower socioeconomic status often have less access to resources in their network, affecting the types of support exchanges in which they can engage (Gallo, Bogart, Vranceanu, \& Matthews, 2005). Without analyses that control for these variables directly it is impossible to determine whether potential differences in the social networks of Black and White couples are correlates of these demographic and economic differences between Black and White couples, or differences independently associated with race.

\section{Overview of the Current Study}

To date, research devoted to understanding persistent racial disparities in marital outcomes has emphasized the relative economic disadvantage of Black couples. The goal of the current study was to evaluate whether Black couples begin their marriages with relative social disadvantages as well, as observed in the composition and structure of their social networks. Toward that end, we examined data from extensive social network interviews conducted with Black and White first-married newlywed couples sampled from low-income communities. Because low-income communities are where racial disparities in marital outcomes are most persistent, low-income couples comprise a particularly appropriate 
sample in which to investigate these issues. Restricting attention to newlyweds ensures that all couples are at a similar stage of their marriage and that the most vulnerable couples have not yet left the population through divorce. Because intermarriages (i.e., those including individuals from different racial or ethnic backgrounds) face unique challenges (e.g., Karis, 2003; Tucker \& Mitchell-Kernan, 1990; Usita \& Poulsen, 2003), they were not included in this study.

On the basis of prior research, we predicted that the composition and structure of Black couples' social networks would reflect less social capital than the networks of comparable White couples; that is, we expected Black couples to describe networks containing fewer sources of support, fewer married individuals, and more divorced individuals than the networks described by White couples. Moreover, we expected Black couples' networks to demonstrate lower spouse centrality and less overlap and for there to be fewer positive relationships among the overlapping network members. We made no predictions about whether observed differences in social network features would be reduced or eliminated after controlling for economic and demographic differences between Black and White couples.

\section{Method}

Newlywed couples were identified via marriage license records obtained from the Los Angeles County Recorder's Office between 2009 and 2010 as part of a larger study on newlywed development among couples living in low-income communities. Using zip codes from marriage license databases, recently married couples' addresses were matched with census data to identify those living in low-income communities. Low-income neighborhoods were identified as those with a median household income of no more than $160 \%$ of the federal poverty level for a four-person family. A similar method was used previously (Bramlett \& Mosher, 2002) and is known to be more reliable than asking participants their income, given that individuals can be reluctant to disclose this information.

Names on the marriage licenses were processed using a Bayesian Census Surname Combination developed by researchers at the RAND Corporation (Elliott et al., 2013). This algorithm integrates census and surname information to produce a multinomial likelihood of each individual falling within one of four racial categories: Black, Hispanic, Asian, and White/Other. Couples identified as having a high probability of being Black or White were contacted for recruitment into a longitudinal study. Follow-up phone calls were made, and those who were eligible and provided consent were included in the study. The seven eligibility criterion included the following: (a) first marriage for each partner, (b) married less than 3 months at the time of screening, (c) spoke fluent English (but do not need to be literate, because data were collected in person or via the telephone), (d) living together (i.e., the couple could not be temporarily separated, nor could either partner be deployed or incarcerated), (e) were above 18, (f) wives were below 40 years of age (to allow for the transition to parenthood for all couples), and (g) both spouses self-identified as either nonHispanic Black or non-Hispanic White. 


\section{Participants}

Using these eligibility criteria, 71 Black couples and 66 White couples were screened as eligible for the study and agreed to participate. Of these, 51 Black (72\%) and 50 White $(76 \%)$ couples were successfully scheduled and completed the baseline interviews. Nine months after the baseline assessment, $86 \%$ of participating couples ( $n=87$ couples) completed the Time 2 interview. The social network interview was completed by $70 \%$ of those who successfully completed a Time 2 assessment, which yielded 30 duocentric White couples' networks, 27 duocentric Black couples' networks, and networks from two additional wives (not analyzed here). Couples who completed the social network interviews $(n=57)$ did not differ significantly from those who did not $(n=44)$ in age, average household income reported at baseline, parental status, or baseline measures of relationship satisfaction. There were also no differences in retention rates across Black and White couples.

Across the 57 couples who provided complete network interviews, the mean length of marriage at baseline was 4.9 months $(S D=2.3)$. Men's mean age was 29.8 years $(S D=6.0)$, and women's mean age was 28.0 years $(S D=4.3)$. However, there were significant differences in age by race, such that Black husbands $(M=28.2)$ and wives $(M=26.6)$ were younger than White husbands $(M=31.3)$ and wives $(M=29.2$; for husbands: $t[55]=2.0, p$ $=.06$; for wives: $t[55]=2.4, p=.02$ ). Wives and husbands self-reported joint household income averaged about $\$ 61,000(S D=\$ 30,000)$, but again this varied significantly by race, such that Black couples $(M=\$ 42,000, S D=\$ 25,000)$ made an average income nearly half that of the White couples $(M=\$ 78,000, S D=\$ 22,000), t(53)=5.7, p<.001$, despite being sampled from similarly low-income neighborhoods. Couples had a mean of 0.51 children ( $S D=0.67)$, with 28 couples having at least one child in the household $(6.7 \%$ of White couples and $44.4 \%$ of Black couples). These three significant demographic differences between Black and White couples-age, income, and the presence of children in their household-were treated as covariates in the analyses described below.

\section{Procedure}

At baseline, couples were visited in their homes by two trained interviewers who described the institutional review board-approved study and obtained consent from each participant. Demographic information was collected in the interviews at this time. Nine months later, couples completed a second interview assessment and were asked to schedule a separate social network interview within the following 2 weeks. At that time, two interviewers arrived at the couple's residence and conducted the network interview separately with each spouse. At the end of each phase of assessment, couples were debriefed and compensated in cash for their time.

\section{Measures}

Demographic information-Demographic data were collected at the baseline interview. Each participant's date of birth, date of marriage, household income, and whether the couple had any children were all collected at this time. Age and marital length at the baseline interview were calculated from the self-reported birth date and marriage date. To measure household income, husbands and wives were independently asked "Thinking about your 
income and the income of everyone else in your household, what was your total household income from all sources before taxes in the past 12 months?" Husbands' and wives' reports correlated highly $(r=.89)$ and thus were averaged to yield a couple-level household income variable. To assess the presence of children, husbands' and wives were independently asked, "Who lives in your current household (besides the two of you)?" with one of the response options being "your (or your spouse's) children (include biological, adopted, step, and foster children)." If either the husband or wife reported the presence of children in the home, the couple was given a dummy code of 1 for "children present" or 0 for "no children present" (disagreement between couple reports occurred in three of the 57 cases; these couples were coded as having children).

The social network interview-To assess egocentric networks, spouses were each asked to list and describe 40 members of their social network (i.e., alters) and to describe the relationship between every possible dyad combination among the network members. This number of alters gave respondents ample opportunity to report about both close and peripheral ties. Spouses were interviewed separately, and interviews averaged 95 minutes in duration.

Specific instructions for naming the network members were as follows:

To get started, I'd like for you to name 40 people that you know and who know you. Here's the kind of person we are hoping you will name: first, they have to be adults, aged 18 years old or older-do not give me the names of children under age 18; second, these should be people you have had contact with sometime during the past year or so-either face to face, by phone, mail, or email; third, these do not have to be people you like, just people you know and who know you. Let's start by naming your spouse, and after that you can name any adults you know no matter who they are or where they live. Please give us their first and last names.

Remember, all of the information you give us is confidential.

For each of the alters they named, spouses were asked to report the gender (man or woman as response options), ethnicity (White, Black or African American, Hispanic or Latino, Asian or Other as response options), current marital status (yes/no), history of divorce (yes/ no), parental status (yes/no), employment (yes/no), and financial status (doing well/getting by/ struggling as response options). In addition, participants categorized their relationship with each alter (i.e., family member, friend, coworker) and rated the quality of that relationship ( $0=$ "bad," $1=$ "neutral," and $2=$ "good"), whether they could turn to that alter for emotional support or tangible support (i.e., money, transportation, food), as well as whether that alter would turn to them for emotional or tangible support, each responded to in a yes/no format. Using this information, we described network composition by adding the number of alters across the network fitting that category, that is, the number of good relationships in the network (i.e., those not identified as either neutral or negative). Participants were allowed to skip any questions they preferred not to answer or to which they did not know the answer. Social network composition data were missing in about 5\% of cases; for each analysis, all available data were analyzed. 
After describing the composition of the network, the following instructions prompted spouses to describe the structure of their networks:

Going back to the list of 40 people that you mentioned earlier, I am going to ask you about pairs of these people and whether they have had contact with each other sometime during the past year or so-either face to face, by phone, or e-mail. For each pair, I want to know if the two people have had any contact.

This part of the interview allowed us to assess the structural variables of interest to the individual networks: density and spouse network centrality. Density was calculated as the number of network members with relationships to one another over the total possible number of relationships; thus, scores ranged from 0 to 1. Spouse network centrality was calculated using spouse degree, which is the number of ties spouses reported their partners had within their individual network.

In addition to looking at the composition and structure of husbands' and wives' individual networks, combining their individual information into a merged network allowed us to examine unique duocentric network features of interest. Shared ties across both spouses were identified by matching the first and last names of the alters reported by each spouse, and these were confirmed by ensuring that shared ties had complementary roles across spouses (e.g., my family as reported by the wife, and my spouse's family as reported by the husband). The number of shared ties that both husbands and wives independently include in their individual networks was treated as an estimate of overlap. In this overlapping region of the duocentric network, we examined the composition (e.g., family vs. friends) as well as the proportion of discordant relationships (i.e., whether a particular alter has a similar quality relationship to both the husband and wife or whether this relationship is negative or neutral for one and positive for the other).

\section{Analysis Strategy}

We estimated social network features for each couple using the igraph package of the $\mathrm{R}$ platform separately for husbands and wives (Csárdi \& Nepusz, 2006). Analyses testing for whether demographic differences between Black and White couples accounted for racial disparities included a dummy variable for race $(1=$ Black, $0=$ White $)$, a dummy variable for parental status ( $1=$ children, $0=$ no children), age (centered and, in the duocentric analyses, averaged across husbands and wives), and household income (centered). To compare the social networks of Black and White couples, we ran stepwise multiple regression models predicting each network feature from race in the first step and race plus the proximal demographic differences between Black and White couples-age, parental status, and household income -in the second step. This allowed us to look for the predicted racial differences consistent with prior literature on Black families and then to determine whether any observed differences were reduced or eliminated after controlling for demographic differences between Black and White couples. 


\section{Results}

\section{Preliminary Analyses}

Correlations among the features of husbands' and wives' networks are presented in Table 1. Patterns of correlation among the social network variables were similar for husbands and wives, although correlations were often weaker and less frequently significant for husbands than wives. Among compositional features, the number of alters needing emotional and tangible support was significantly positively associated with the number of alters providing tangible and emotional support for both spouses. For wives, the provision and receipt of both forms of support were also significantly positively associated with the number of good quality relationships and the number of married individuals in the network. For husbands, associations between support exchange and the quality and composition of the network were weaker but were generally in the same directions. With respect to the structure of husbands' and wives' social networks, the density of wives' networks was significantly positively associated with all forms of support exchange, and wives' report of spouse degree was significantly positively associated with the number of alters needing emotional or tangible support. For husbands, these associations were weaker and less frequently significant, but in the same direction. Features of husbands' and wives' networks were significantly positively correlated between partners for only two of the 11 characteristics assessed: (a) number of own family members and (b) number of married alters.

With respect to the features of the combined duocentric networks, the number of overlapping alters was significantly negatively associated with the proportion of family members in the overlapping region for both spouses; that is, the more that both spouses shared individuals in their networks, the less likely those individuals were to be their family members. The number of overlapping ties was also significantly positively associated with the number of married individuals in each spouse's individual networks, suggesting that couples who interact with more married people are also more likely to share network ties.

Race was separately examined as a moderator of each of the 91 correlations across all combinations of the 13 social network variables. For wives, none of the 91 correlations were significantly different between racial groups. For husbands, five of the 91 correlations differed significantly between racial groups. Thus, the vast majority of the network features correlated similarly across groups and in the expected directions, justifying further analyses of these variables. Moreover, the modest correlations indicate that these features of social networks are relatively independent, warranting their treatment as unique variables of interest in further analyses.

\section{Racial Differences in Individual Network Composition}

In Table 2 we present unstandardized beta coefficients and standard errors testing for racial differences in individual network composition. In contrast to the suggestion that Black couples may maintain closer ties with their social networks than White couples (Broman, 1996; McAdoo, 1998), Black wives reported having significantly fewer positive relationships in their network than did White wives. Specifically, White wives, on average, rated 34.2 of their 40 network ties as positive relationships, whereas Black wives 
characterized only 30.7 of their 40 network ties as positive, on average $(p<.05)$. Black and White husbands' did not significantly differ in the number of positive relationships in their network; neither did they significantly differ from White wives.

With respect to the types of relationships in husbands' and wives' networks, Black husbands and wives included nearly twice as many of their own family members in their network as White husbands and wives (for Black husbands, $M=12.2, S D=7.3$, for Black wives, $M=$ 12.4, $S D=6.0$, for White husbands, $M=6.5, S D=5.0$, for White wives, $M=6.7, S D=4.2$; $p<.001$ for both wife and husband comparisons). In contrast, Black husbands included significantly fewer members of their spouses' family than did White husbands (for White husbands, $M=3.0, S D=2.1$, for Black husbands, $M=1.7, S D=1.9 ; p=.03$ ). Black and White wives did not differ significantly in the number of their spouses' family members included in their individual networks.

Considering the intersection between relationship type and relationship quality, further analyses revealed that Black and White husbands did not differ in the number of negative relationships with their wives' family members but that Black husbands $(M=1.37, S D=$ 1.6) reported significantly fewer positive relationships with their wives' family members than did White husbands $(M=2.8, S D=2.0, p<.01)$. No significant difference in the quality of in-law relationships was observed between Black and White wives' social networks $(p>.05)$.

The fact that Black wives and husbands included more family members in their networks raises the possibility that Black couples could access more support from their networks than White couples, given that people are most likely to receive support from family (Wellman \& Wortley, 1990). These data offered no support for this idea. On the contrary, neither wives nor husbands differed significantly by race in the number of sources of tangible support, and White and Black husbands did not differ significantly in the number of sources of emotional support from their network. The one significant racial difference in support exchange was a relative disadvantage for Black couples, such that Black wives perceived having significantly fewer ties in their network to which they could turn for emotional support than did White wives. With respect to the demands made by network members, Black and White couples did not differ significantly in the number of people they believed would seek emotional or tangible support from them; neither did they differ in the number of people who were financially struggling in their networks $(p>.05)$.

Not surprisingly, $80 \%$ of Black couples' network members were Black individuals, and $82 \%$ of White couples' network members were White individuals. Consistent with national trends showing that Black couples have lower rates of marriage than White couples, Black husbands and wives reported that about one third of their networks consisted of currently married individuals (for husbands, $M=11.8, S D=6.5$; for wives, $M=12.3, S D=5.7$ ), whereas White husbands and wives reported that nearly half of the individuals in their networks were married (for husbands, $M=18.2, S D=5.5$; for wives, $M=18.4, S D=6.1$ ). Black and White couples did not differ significantly in the number of divorced network members in their networks. 
To evaluate the extent to which the observed differences in the composition of Black and White spouses' social networks can be attributed to economic and demographic differences between the two groups, Table 2 also provides tests of racial differences in each of these compositional features after adjusting for between-group differences in age, income, and parental status. For wives, all of the significant differences in social network composition were reduced to nonsignificance when including economic and demographic variables; that is, the social disadvantages observed in the networks of Black wives relative to White wives could be attributed to the fact that Black wives in this sample were younger, more likely to be parents, and earned less income than the White wives in this sample. For husbands, most of the significant differences between Blacks and Whites in the composition of their networks could similarly be explained by economic and demographic variables, but Black husbands were still found to include fewer of their wives' family members within their networks even after including the control variables than White husbands. Thus, the reduced number of connections between Black husbands and their wives' families relative to White husbands is not merely a function of demographic differences between these groups.

\section{Racial Differences in Individual Network Structure}

Also presented in Table 2 are unstandardized beta coefficients and standard errors testing for racial differences in the density of spouses' individual networks and the centrality of one's partner in their network (spouse degree). As the data reveal, Black and White husbands' and wives' networks did not differ significantly in density, but did differ significantly in spouse degree, such that Black wives reported their husbands as having significantly a lower degree (i.e., fewer connections to other members of the wife's network) than White wives reported for their husbands. This difference was fully accounted for by demographic differences between Black and White wives. Spouse degree reported by Black and White husbands did not differ significantly.

\section{Racial Differences in Duocentric Social Networks}

Unstandardized beta coefficients and standard errors testing for racial differences in characteristics of couples' duocentric networks - specifically, the number of overlapping individuals, the proportion of family members in the overlapping region, and the proportion of discordant relationships in the overlapping region-are presented in Table 3. As the data reveal, Black and White couples differed significantly in the number of overlapping network members, such that Black couples had less than half of the shared ties of the White couples (for Black couples, $M=6.5, S D=4.0$; for White couples, $M=13.5, S D=5.2 ; p<.001$ ). This difference remained significant after adjusting for the couples' parental status, age, and household income.

Within these overlapping portions of their networks Black couples included a significantly greater proportion of family than did White couples. For Black couples, family members comprised $56 \%$ of overlapping alters on average, whereas for White couples family members comprised 39\% of overlapping alters on average. This difference was reduced to nonsignificance when age, parental status, and income were controlled. 
Consistent with our prediction, spouses' relationships with their overlapping network members were significantly more discordant for Black couples than White couples. Among the Black couples, about $64 \%$ of the shared alters have a positive relationship with one spouse but a negative or neutral relationship with the other. Discordant relationships such as this characterized only $22 \%$ of the shared relationships among White couples. This difference remained significant even after demographic differences between Black and White couples were controlled.

In cases where racial differences between Black and White couples were reduced to nonsignificance, post hoc analyses (not reported here) revealed no consistent patterns across the husbands' and wives' individual networks and their duocentric network for which of the three control variables were most influential in accounting for racial differences across the networks.

\section{Discussion}

In the current study, we drew on extensive social network interviews with recently married Black and White couples to explore whether low-income Black couples enter their marriages with social disadvantage relative to Whites or whether, as some have argued (e.g., Hill, 1999; McAdoo, 1998), social networks may be a unique source of strength for lowincome Black couples and thus a possible way to compensate for a lack of financial resources.

The results of these analyses support two general conclusions. First, in addition to their relative economic disadvantages, Black couples in low-income communities enter their marriages with several social disadvantages relative to White couples living in similar neighborhoods. For example, compared to the White couples, the Black couples in this sample began their marriages embedded in networks that included more family members, but Black wives nevertheless reported fewer sources of emotional support within their networks, and fewer good quality relationships more generally, than White wives did. Existing research has observed similar differences in the support networks available to Black and White women, attributing the differences to Black women's accumulated experiences with family disruption (e.g., Neighbors, 1997; Sarkisian \& Gerstel, 2004). The current findings suggest that, even among partnered women who have yet to experience marital disruption themselves, Black wives may already have less access to the sorts of relationships that might promote the stability of their marriages. Consistent with this view, Black husbands and wives also included significantly fewer married individuals in their networks than White husbands and wives did. Booth et al. (1991) argued that younger couples navigating the transition into marriage are especially likely to benefit from access to other couples who have negotiated that transition successfully. To the extent that Black spouses have access to fewer of these couples at the outset of their marriages, they may lack exposure to norms of marital stability during the period when such exposure is particularly important.

The second general conclusion supported by these results is that most of the social disadvantages of low-income Black couples entering marriage covary with economic and 
demographic differences between Black and White couples. Consistent with prior research on social support in Black and White families (Sarkisian \& Gerstel, 2004), most of the significant differences in the composition of Black and White social networks were eliminated after controlling for differences in income, age, and parental status between Black and White couples. Nevertheless, important differences between Black and White couples remained significant even after adjusting for economic differences. The most striking social disadvantages for Black couples emerged not in the composition of spouses' individual networks but in the structure of their combined networks, and these differences remained significant, and were even slightly higher, after adjusting for control variables. On average, the overlap within Black couples' duocentered networks contained only half as many individuals as the overlap within White couples' networks. Within that area of overlap, Black couples were more likely to report discordant relationships, that is, individuals with a positive relationship with one spouse but a neutral or negative relationship with the other spouse. Combined with the finding that Black husbands include fewer of their wives' family members in their networks than White husbands, these results indicate that Black couples begin their marriages with less integrated social networks than their similarly situated White peers.

Given that these structural differences are independent of demographic differences that otherwise distinguish between first-married Black and White newlyweds, why might they emerge? One possibility is that Black spouses are less likely to engage with each other's networks. If the networks of Black couples contain fewer people with available resources, Black spouses may see fewer benefits in connecting with each other's family and friends and so may not exert the effort it takes to do so (Roschelle, 1997). An alternative (but compatible) possibility is that the networks of Black spouses are less likely to welcome and embrace both members of a couple. To the extent that members of the network surrounding a couple are aware of the higher vulnerability of Black marriages, they may see more risks in investing in a relationship that they perceive is likely to end. Evaluating the evidence for these explanations is a task for future research, but either possibility leaves Black couples lacking a social context that is associated with more stable and satisfying marriages among White couples (Burger \& Milardo, 1995; Kearns \& Leonard, 2004).

\section{Strengths and Limitations}

Several strengths of the current study heighten our confidence in these results. First, whereas prior research comparing Black and White social networks has frequently confounded race, class, and marital status, all of the couples we examined were first-married newlyweds sampled from similarly low-income neighborhoods. Second, whereas prior studies of social networks have relied on individuals' perceptions of their networks as a whole, the network characteristics we examined were derived from social network interviews that assessed each of 40 network members individually, offering details about network composition and structure that spouses would not have been able to identify when asked more globally. Third, whereas prior studies of racial differences in social networks have relied on reports from individuals, in the current study we were able to examine duocentric networks assembled from interviews with both spouses in each couple. 
Despite these strengths, interpretations of the current study must also be tempered by several limitations. First, although all couples were recruited using the same procedures and from the same neighborhoods, Black couples nevertheless differed from the White couples in numerous ways. Three notable differences (income, age, and parental status) were identified and controlled, but additional uncontrolled differences may yet account for the persistent racial differences observed here. Second, although the current study identified racial differences in characteristics of social networks that have been associated with marital outcomes such as satisfaction and divorce, the links between those network characteristics and subsequent marital outcomes were not examined. A priority for future research is to examine whether differences in social networks among Black and White couples beginning their marriages account for racial disparities in their subsequent marital outcomes. Third, these social network data were obtained at a single moment in these couples' lives. Without longitudinal data, we cannot know whether the social network features described here are stable or whether they change over time and thus may be the consequences of marital outcomes rather than potential causes. Fourth, although the relative homogeneity of the couples we examined is beneficial for limiting the potential for confounds associated with marital duration and economic status, it also limits our ability to extend the conclusions of this research to other populations. In particular, the same racial differences may not describe the social networks of older couples, where higher divorce rates among Blacks may lead to greater differences between Black and White couples who remain intact, or these data may not represent couples who do not marry.

\section{Implications for Theory and Intervention}

Evidence for differences in the social networks of Black and White low-income couples at the outset of their marriages has implications for both theory and intervention. With respect to theory, the current findings draw attention to the distinct views of low-income marriage that emerge from ethnographic versus quantitative research. Ethnographies of Black families and marriages have frequently emphasized the independence of economic and social resources in low-income communities, suggesting that low-income families, and Black families in particular, invest in their social networks, building social capital to compensate for a relative lack of financial capital (Hill, 1999; McAdoo, 1998). The current analyses reveal no support for such a view. Instead, social capital and financial capital appear strongly and positively associated, such that couples who possess the least financial capital (i.e., lowest incomes) are those with the least social capital (i.e., fewer positive relationships, fewer sources of support, less overlap between spouses). Additional support for this finding would suggest that developing social capital may not come easily for couples who are also struggling financially.

With respect to intervention, further support for this perspective would highlight new directions for efforts to support low-income families, and low-income Black marriages in particular. Current efforts to improve the relationships of low-income couples focus almost exclusively on interventions targeting the way partners communicate and resolve problems with each other (Ooms, 2005). To date, evaluations of the impact of such programs on marital outcomes in low-income communities have proven disappointing (Wood, McConnell, Moore, \& Clarkwest, 2010). We suggest expanding the focus of these efforts to 
include the way spouses interact with members of their own and each other's social networks. There may be approaches to one's community (e.g., selecting people with whom to interact, making an effort to be closer to each other's friends and family) that could affect couples' ability to maintain their marriages (Cohen \& Janicki-Deverts, 2009). Put more broadly, acknowledging the social disadvantages that some couples face may direct the attention of policymakers toward interventions that address social networks themselves as targets of change.

\section{Acknowledgments}

NOTE

Preparation of this report was supported by Research Grants HD053825 and HD061366 from the National Institute of Child Health and Human Development awarded to Benjamin R. Karney.

\section{References}

Ajrouch KJ, Antonucci TC, Janevic MR. Social networks among Blacks and Whites: The interaction between race and age. Journals of Gerontology Series B: Psychological Sciences and Social Sciences. 2001; 56B:S112- S118.10.1093/geronb/56.2.S112

Allan, G. Social networks and personal communities. In: Vangelisti, AL.; Perlman, D., editors. The Cambridge handbook of personal relationships. New York: Cambridge University Press; 2006. p. 657-671.

Booth A, Edwards JN, Johnson DR. Social integration and divorce. Social Forces. 1991; 70:207224.10.1093/sf/70.1.207

Bost KK, Cox MK, Payne C. Structural and supportive changes in couples' family and friendship networks across the transition to parenthood. Journal of Marriage and Family. 2002; 64:517531.10.1111/j.1741-3737.2002.00517.x

Bramlett, MD.; Mosher, WD. Vital and Health Statistics. Vol. 23. Hyattsville, MD: National Center for Health Statistics; 2002. Cohabitation, marriage, divorce, and remarriage in the United States. Retrieved from www.cdc.gov/nchs/data/series/sr_23/sr23_022.pdf

Broman CL. The health consequences of racial discrimination: A study of African Americans. Ethnicity \& Disease. 1996; 6:148-153. [PubMed: 8882843]

Brown, E.; Orbuch, TL.; Maharaj, A. Social networks and marital stability among Black American and White American couples. In: Sullivan, KT.; Davila, J., editors. Support processes in intimate relationships. New York: Oxford University Press; 2010. p. 318-334.

Bryant CM, Wickrama KAS, Bolland J, Bryant BM, Cutrona CE, Stanik CE. Race matters, even in marriage: Identifying factors linked to marital outcomes for African Americans. Journal of Family Theory \& Review. 2010; 2:157-174.10.1111/j.1756-2589.2010.00051.x

Burger E, Milardo RM. Marital interdependence and social networks. Journal of Social and Personal Relationships. 1995; 12:403-415.10.1177/0265407595123005

Carstensen LL. Social and emotional patterns in adulthood: Support for socioemotional selectivity theory. Psychology and Aging. 1992; 7:331-338.10.1037/0882-7974.7.3.331 [PubMed: 1388852]

Centola D. The spread of behavior in an online social network experiment. Science. 2010 Sep 3.329:1194-1197.10.1126/science.1185231 [PubMed: 20813952]

Chatters LM, Taylor RJ, Jayakody R. Fictive kinship relations in Black extended families. Journal of Comparative Family Studies. 1994; 25:297-312.

Cohen S, Janicki-Deverts D. Can we improve our physical health by altering our social networks? Perspectives on Psychological Science. 2009; 4:375-378.10.1111/j.1745-6924.2009.01141.x [PubMed: 20161087]

Coromina L, Guia J, Coenders G, Ferligoj A. Duocentered networks. Social Networks. 2008; 30:49_ 59.10.1016/j.socnet.2007.07.001 
Csárdi, G.; Nepusz, T. The igraph software package for complex network research. InterJournal Complex Systems. 2006. Retrieved from http://www.necsi.edu/events/iccs6/papers/ c1602a3c126ba822d0bc4293371c.pdf

Elliott MN, Becker K, Beckett MK, Hambarsoomian K, Pantoja P, Karney B. Using indirect estimates based on name and census tract to improve the efficiency of sampling matched ethnic couples from marriage license data. Public Opinion Quarterly. 2013; 77:375-384.10.1093/poq/nft007

Elwood, DT.; Jencks, C. The uneven spread of single-parent families: What do we know? What do we need to know? Where do we look for answers? In: Neckerman, KM., editor. Social inequality. New York: Russell Sage Foundation; 2004. p. 3-118.

Fronczek, P. Income, earnings, and poverty from the 2004 American Community Survey. Washington, DC: U.S. Census Bureau; 2005. Retrieved from www.census.gov/prod/2007pubs/acs-08.pdf

Gallo LC, Bogart L, Vranceanu A, Matthews KA. Socioeconomic status, resources, psychological experiences, and emotional responses: A test of the reserve capacity model. Journal of Personality and Social Psychology. 2005; 88:386-399.10.1037/0022-3514.88.2.386 [PubMed: 15841865]

Golinelli D, Ryan G, Green HD, Kennedy DP, Tucker JS, Wenzel SL. Sampling to reduce respondent burden in personal network studies and its effect on estimates of structural measures. Field Methods. 2010; 22:217-230.10.1177/1525822X10370796 [PubMed: 21113275]

Harknett K, Knab J. More kin, less support: Multipartnered fertility and perceived support among mothers. Journal of Marriage and Family. 2007; 69:237-253.10.1111/j.1741-3737.2006.00356.x

Hill, RB. The strengths of Black families: Twenty-five years later. Lanham, MD: University Press of America; 1999.

Julien D, Chartrand E, Begin J. Social networks, structural interdependence, and conjugal adjustment in heterosexual, gay, and lesbian couples. Journal of Marriage and the Family. 1999; 61:516530.10.1037/0893-3200.18.2.383

Karis TA. How race matters and does not matter for White women in relationships with Black men. Journal of Couple \& Relationship Therapy. 2003; 2:23-40.10.1300/J398v02n02_03

Kearns JN, Leonard KE. Social networks, structural interdependence, and marital quality over the transition to marriage: A prospective analysis. Journal of Family Psychology. 2004; 18:383395.10.1037/0893-3200.18.2.383 [PubMed: 15222845]

Kennedy, DP.; Jackson, GL.; Bradbury, TN.; Green, HD.; Karney, BR. The analysis of duocentric social networks: A primer. 2014. Manuscript submitted for publication

Landale NS, Oropesa RS. Hispanic families: Stability and change. Annual Review of Sociology. 2007; 33:381-405.10.1146/annurev.soc.33.040406.131655

Lawson E, Thompson A. Historical and social correlates of African American divorce: Review of the literature and implications for research. Western Journal of Black Studies. 1994; 18:91-103.

Macartney, S.; Bishaw, A.; Fontenot, K. Poverty rates for selected detailed race and Hispanic groups by state and place: 2007-2011. Washington, DC: U.S. Census Bureau; 2013. Retrieved from www.census.gov/prod/2013pubs/acsbr11-17.pdf

Marks LD, Hopkins K, Chaney C, Monroe P, Nesteruk O, Sasser D. Together, we are strong: A qualitative study of happy, enduring African American marriages. Family Relations. 2008; 57:172-185.10.1111/j.1741-3729.2008.00492.x

Marsden, PV. Recent developments in network measurement. In: Carrington, PJ.; Scott, J.; Wasserman, S., editors. Models and methods in social network analysis. New York: Cambridge University Press; 2005. p. 8-30.

McAdoo, HP. African American families. In: Mindel, CH.; Habenstein, RW.; Wright, R., editors. Ethnic families in America: Patterns and variations. Upper Saddle River, NJ: Prentice Hall; 1998. p. 361-381.

McDermott, R.; Fowler, JH.; Christakis, NA. Breaking up is hard to do, unless everyone else is doing it too: Social network effects on divorce in a longitudinal sample followed for 32 years. 2009. Retrieved from http://ssrn.com/abstract=1490708

Neighbors, HW. Husbands, wives, family, and friends: Sources of stress, sources of support. In: Taylor, RJ.; Jackson, JS.; Chatters, LM., editors. Family life in Black America. Newbury Park, CA: Sage; 1997. p. 227-292. 
Ooms, T. Couples and Marriage Series Brief No 7. Center for Law \& Social Policy; Washington, DC: 2005. The new kid on the block: What is marriage education and does it work?

Orbuch, TL.; Bauermeister, J.; Brown, E. Family ties and the odds of divorce for Black-American and White-American married couples. Paper presented at the biannual conference of the International Association for Relationship Research; Providence, RI. 2008 Jul.

Rhodes JE, Ebert L, Meyers AB. Social support, relationship problems and the psychological functioning of young African American mothers. Journal of Social and Personal Relationships. 1994; 11:587-599.10.1177/0265407594114006

Roschelle, AR. No more kin: Exploring race, class, and gender in family networks. Thousand Oaks, CA: Sage; 1997.

Roy KM. Transitions on the margins of work and family life for low-income African American fathers. Journal of Family and Economic Issues. 2005; 26:77-100.10.1007/s10834-004-1413-3

Sampson RJ, Morenoff JD, Gannon-Rowley T. Assessing "neighborhood effects": Social processes and new directions in research. Annual Review of Sociology. 2002; 28:443-478.

Sarkisian N, Gerstel N. Kin support among Blacks and Whites: Race and family organization. American Sociological Review. 2004; 69:812-837.10.1177/000312240406900604

Scott, JW.; Black, A. Deep structures of Black family life: Female and male kin networks. In: Staples, R., editor. The Black family: Essays and studies. Belmont, CA: Wadsworth; 1999. p. 232-240.

Sprecher S. The influence of social networks on romantic relationships: Through the lens of the social network. Personal Relationships. 2011; 18:630-644.10.1111/j.1475-6811.2010.01330.x

Stack, CB. All our kin: Strategies for survival in a Black community. New York: Harper \& Row; 1974.

Staples, R.; Johnson, LB. Black families at the crossroads: Challenges and prospects. San Francisco: Jossey-Bass; 1993.

Stein CH, Bush EG, Ross RR, Ward M. Mine, yours and ours: A configural analysis of the networks of married couples in relation to marital satisfaction and individual well-being. Journal of Social and Personal Relationships. 1992; 9:365-383.10.1177/0265407592093003

Timmer SG, Veroff J, Hatchett S. Family ties and marital happiness: The different marital experiences of Black and White newlywed couples. Journal of Social and Personal Relationships. 1996; 13:335-359.10.1177/0265407596133003

Tucker MB, Mitchell-Kernan C. New trends in Black American interracial marriage: The social structural context. Journal of Marriage and the Family. 1990; 52:209-218.

Usita PM, Poulsen S. Interracial relationships in Hawaii: Issues, benefits, and therapeutic interventions. Journal of Couple \& Relationship Therapy. 2003; 2:73-83.10.1300/J398v02n02_06

Wasserman, S.; Faust, K. Social network analysis: Methods and analysis. Cambridge, UK: Cambridge University Press; 1994.

Wellman B, Wortley S. Different strokes from different folks: Community ties and social support. American Journal of Sociology. 1990; 96:558-588.

Wilson, WJ. The truly disadvantaged: The inner city, the underclass, and public policy. Chicago: University of Chicago Press; 1987.

Wood, RG.; McConnell, S.; Moore, Q.; Clarkwest, A. Strengthening unmarried parents' relationships: The early impacts of building strong families. Princeton, NJ: Mathematica Policy Research; 2010. 


\begin{tabular}{|c|c|c|c|c|c|c|c|c|c|c|c|c|c|c|c|}
\hline & \pm & 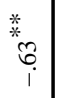 & s. & $\begin{array}{l}t \\
0 \\
i\end{array}$ & $\stackrel{*}{*} \underset{i}{\vec{F}}$ & \begin{tabular}{|c|}
$*$ \\
0 \\
0 \\
1 \\
1
\end{tabular} & $\begin{array}{c}* \\
F_{j} \\
i\end{array}$ & $\mid \begin{array}{l}* \\
2 \\
? \\
i\end{array}$ & $\mid \begin{array}{c}0 \\
1 \\
1 \\
1\end{array}$ & 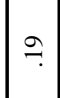 & $\underbrace{a}_{1}$ & $\frac{ \pm}{i}$ & $\bar{a}_{i}$ & بִ & | \\
\hline & $=$ & $\underset{i}{i}$ & $\stackrel{*}{*}$ & * & $\stackrel{\circ}{i}$ & $\begin{array}{c}* \\
\tilde{2} \\
\tilde{1} \\
1\end{array}$ & \begin{tabular}{ll}
$*$ \\
\multirow{2}{*}{} \\
$\stackrel{1}{1}$ \\
1
\end{tabular} & 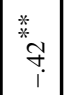 & 俈 & 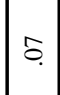 & $\because$ & \begin{tabular}{|c|}
$*$ \\
$*$ \\
$*$ \\
0 \\
1
\end{tabular} & $\begin{array}{c}* \\
\stackrel{*}{*} \\
i \\
1\end{array}$ & | & ְ̊ \\
\hline & $\approx$ & ชุ. & $\stackrel{*}{*} \stackrel{*}{*}$ & $\stackrel{t}{\sim}$ & $\stackrel{\infty}{6}$. & 8 & 8 & $\stackrel{\overbrace{}}{~}$ & 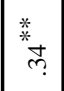 & $\because$ & $\tilde{\Upsilon}$ & * & 1 & 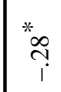 & $\begin{array}{l}\bar{c}_{i} \\
\end{array}$ \\
\hline & $=$ & $\because$ & 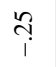 & $\stackrel{\infty}{\hookrightarrow}$ & $\vec{\Upsilon}$ & 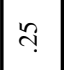 & \begin{tabular}{|l|}
$*$ \\
$*$ \\
$m$ \\
$m$
\end{tabular} & \begin{tabular}{|l|}
$*$ \\
$*$ \\
$\vec{n}$
\end{tabular} & \begin{tabular}{|l|}
$*$ \\
$*$ \\
$*$ \\
\end{tabular} & t. & ${ }^{*} \infty$ & ণิ & \begin{tabular}{|c|}
$*$ \\
$*$ \\
$\infty$ \\
$\infty$
\end{tabular} & $\stackrel{7}{i}$ & $\because$ \\
\hline & 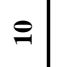 & $\bar{c}_{i}$ & $\bar{\sigma}$ & $\stackrel{?}{\imath}$ & *ั) & 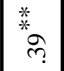 & ${ }^{*} \infty$ & $\begin{array}{l}* \\
\forall \\
\end{array}$ & ণิ & $\delta$ & $\bar{c}_{i}$ & $\frac{n}{i}$ & $\overline{0}_{i}$ & 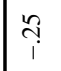 & $\underset{i}{0}$ \\
\hline & $a$ & $\stackrel{\circ}{i}$ & $\tilde{i}_{i}$ & o. & ণิ & $\because$ & 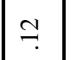 & $=$ & $\div$ & $\because$ & $\tilde{\delta}_{i}$ & 8 & $F_{i}$ & $\because$ & ${ }^{*}{ }^{\circ} \mathrm{c}$ \\
\hline 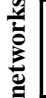 & $\infty$ & ণิ & $\stackrel{9}{1}$ & 8 & * & $\begin{array}{ll}* \\
\\
\end{array}$ & \begin{tabular}{|l|}
\multirow{*}{*}{} \\
f. \\
\end{tabular} & \begin{tabular}{|l|}
$*$ \\
$*$ \\
$*$ \\
$q$ \\
$q$
\end{tabular} & \begin{tabular}{|l|}
$*$ \\
$*$ \\
$\vec{n}$
\end{tabular} & $\bar{i}_{i}$ & $\stackrel{+}{\leftrightarrow}$ & $\simeq$ & ${ }^{*}{ }_{\uparrow}$ & $\begin{array}{l}\dddot{\imath} \\
i\end{array}$ & $\frac{9}{1}$ \\
\hline 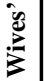 & - & 菜 & $\stackrel{\simeq}{i}$ & o̊ & * & 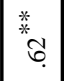 & $\begin{array}{l}* \\
* \\
\vdots \\
6 \\
6\end{array}$ & $\stackrel{1}{7}$ & * & $\begin{array}{l}8 \\
i\end{array}$ & 誊 & to & $\stackrel{n}{i}$ & 8 & $\overrightarrow{0}_{i}$ \\
\hline & 6 & $\stackrel{*}{*} \underset{f}{q}$ & $\therefore$ & $\overline{0}$ & $\frac{\sqrt{*}}{*_{0}^{*}}$ & \begin{tabular}{|l|}
$*$ \\
$*$ \\
$*$ \\
$\infty$ \\
$\infty$
\end{tabular} & $\because$ & \begin{tabular}{|l|}
$*$ \\
$*$ \\
$*$ \\
\multirow{f}{*}{}
\end{tabular} & 8 & 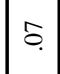 & $\bar{\Upsilon}$ & o. & $\underset{i}{7}$ & $\delta$ & o. \\
\hline & in & $\stackrel{*}{*}$ & $\stackrel{8}{\circ}$ & ô. & $\stackrel{*}{*}$ & $\frac{0}{1}$ & * & \begin{tabular}{|l|}
$*$ \\
$*$ \\
$*$ \\
\multirow{f}{*}{+}
\end{tabular} & \begin{tabular}{|l}
$*$ \\
$*$ \\
\end{tabular} & t. & ฯ & $\stackrel{\infty}{\circ}$ & $\overbrace{i}^{n}$ & \pm & $\overline{0}_{i}$ \\
\hline & + & $\underset{*}{*}$ & $\stackrel{9}{i}$ & ợ & $\simeq$ & \begin{tabular}{|l|}
$*$ \\
$*$ \\
*n \\
in
\end{tabular} & * & 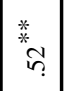 & ণิ & $\because$ & 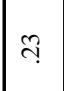 & $\stackrel{\infty}{-}$ & $\underset{i}{i}$ & $=$ & $\hat{o}$ \\
\hline & $\infty$ & $\stackrel{\varphi}{\circ}$ & $\stackrel{\infty}{0}$ & of & 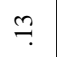 & $\because$ & $\underset{i}{\stackrel{2}{*}}$ & $\hat{a}_{i}$ & $\because$ & $\overline{0}$ & $=$ & $\mid \begin{array}{l}s_{0} \\
i\end{array}$ & ${ }^{*}$\begin{tabular}{c}
$\infty$ \\
\hdashline
\end{tabular} & भy & $\tilde{\delta}$ \\
\hline & $\sim$ & 7 & 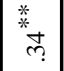 & $\stackrel{\infty}{0}$ & $\stackrel{\infty}{\longrightarrow}$ & * & t & $=$ & 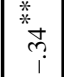 & \pm & $\bar{F}_{i}$ & $\begin{array}{l}\tilde{c} \\
\mathrm{i}\end{array}$ & 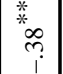 & \begin{tabular}{|l}
$*$ \\
$*$ \\
$*$ \\
\multirow{f}{*}{+}
\end{tabular} & 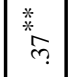 \\
\hline & -1 & $\underset{i}{i}$ & $\begin{array}{c}* \\
\stackrel{*}{\sim} \\
\end{array}$ & $\bar{c}_{i}$ & 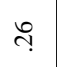 & ণิ & ${ }^{*} \bar{m}$ & $\begin{array}{l}* \\
m \\
m\end{array}$ & 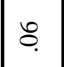 & $\widetilde{?}$ & o. & $\approx$ & $\overline{0}$ & ণ़่ & \begin{tabular}{|l|}
$*$ \\
$*$ \\
$\infty$ \\
$m$
\end{tabular} \\
\hline 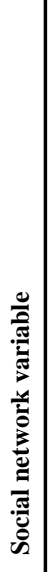 & 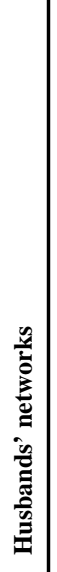 & 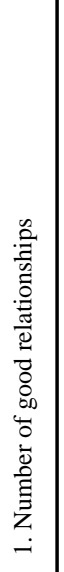 & 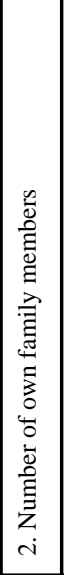 & 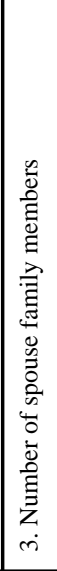 & 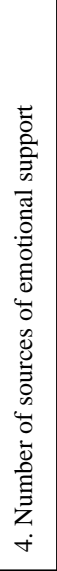 & 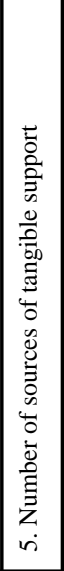 & 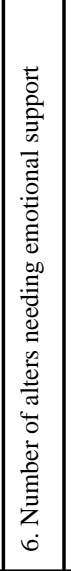 & 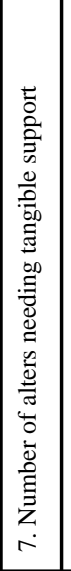 & 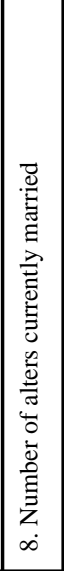 & 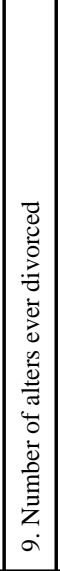 & 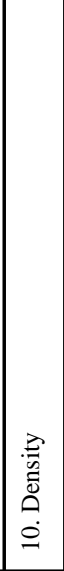 & 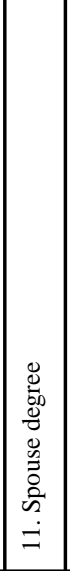 & 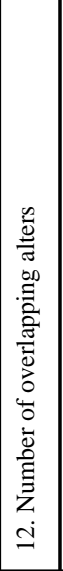 & 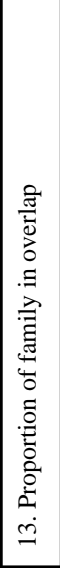 & 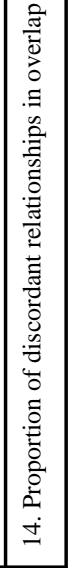 \\
\hline
\end{tabular}




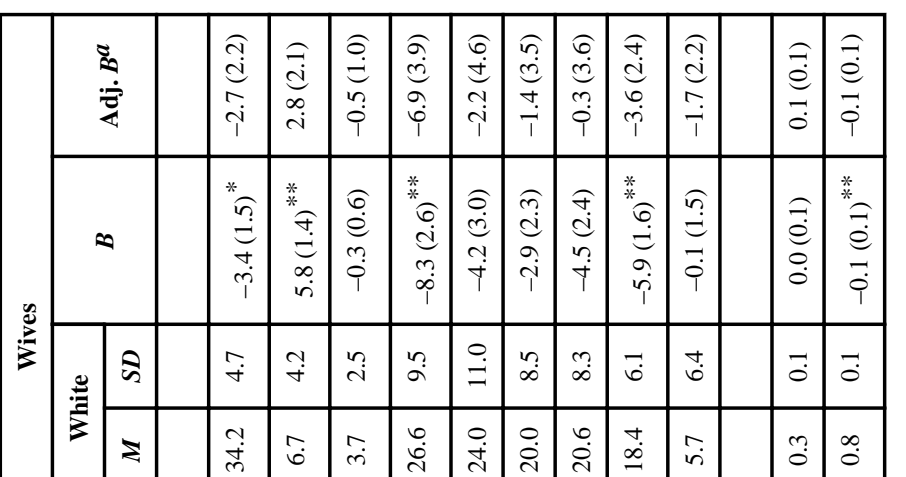

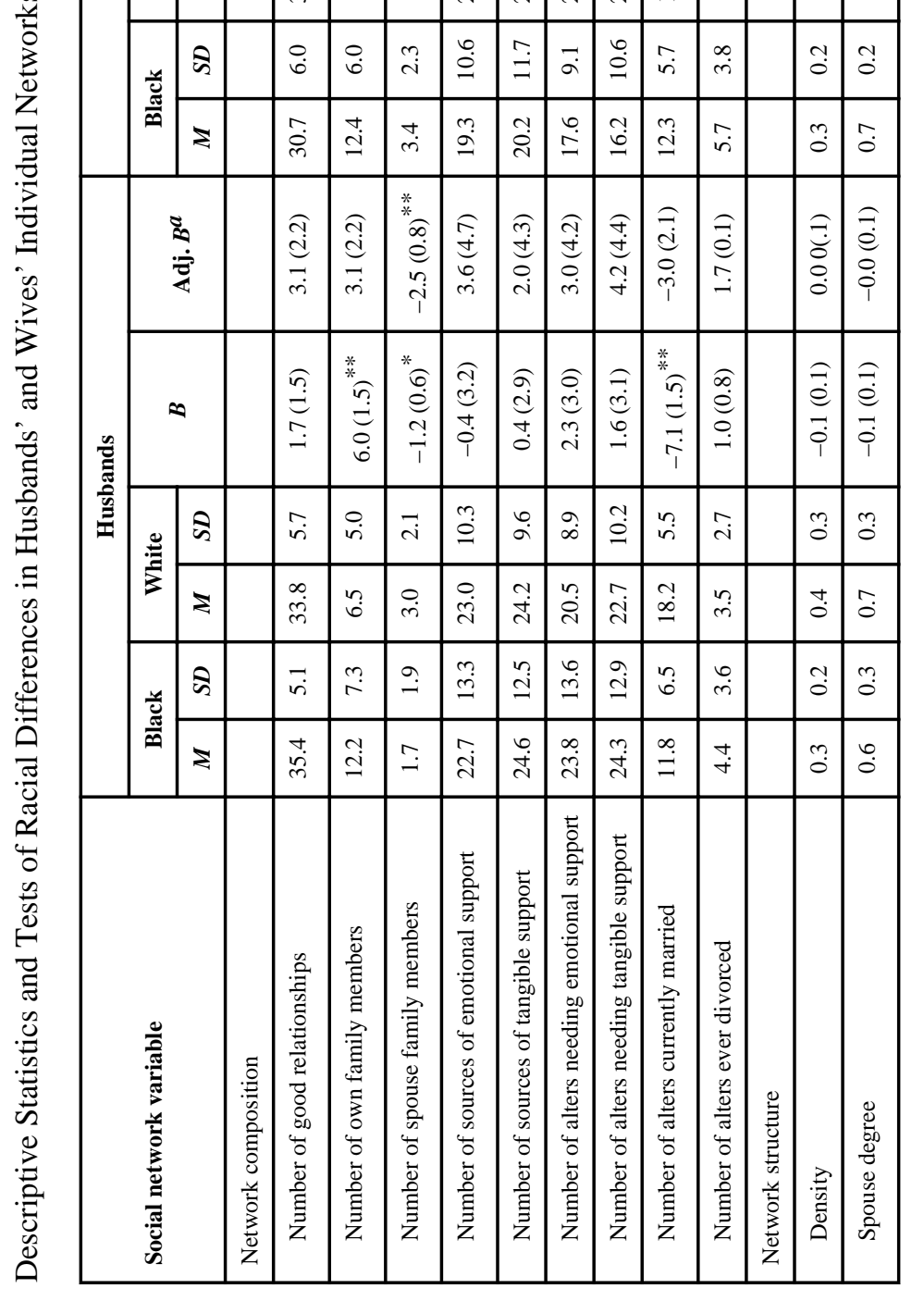

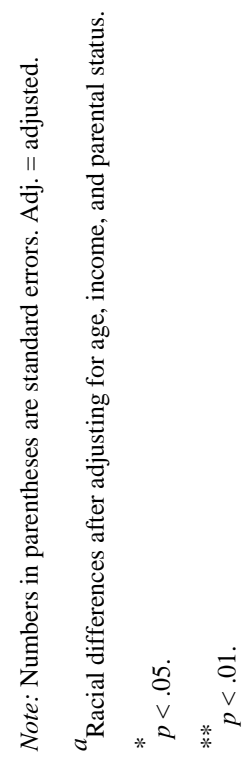




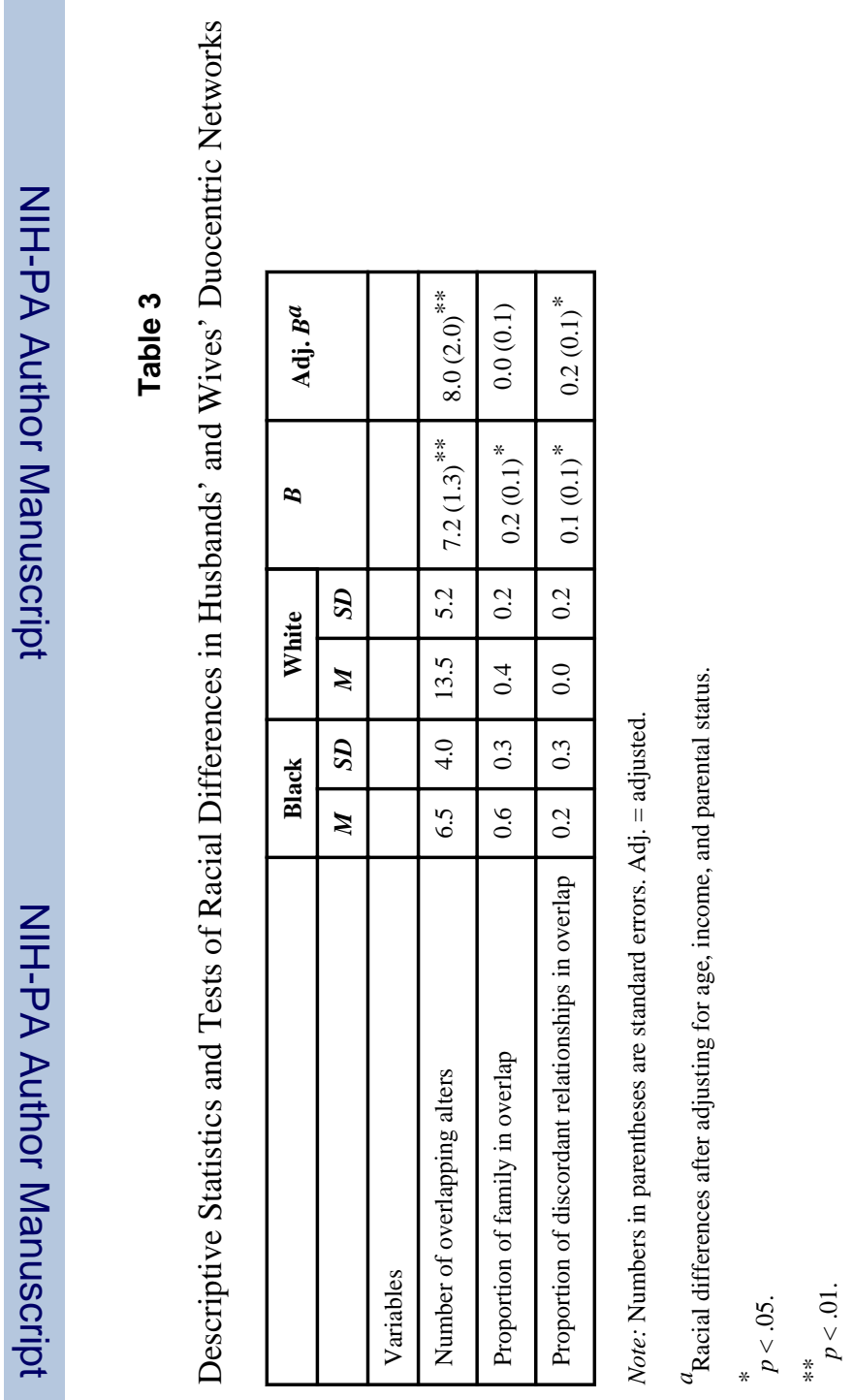

